\title{
ASSESSMENT OF THE CAN BUS TECHNOLOGY IMPLEMENTED ON MODERN AGRICULTURAL TRACTORS TO STUDY FUEL CONSUMPTION SAVINGS
}

\author{
Guillaume DEFAYS \\ Walloon Agricultural Research Centre, BELGIUM \\ E-mail of corresponding author: g.defays@cra.wallonie.be
}

Keywords: CAN Bus, tractor, fuel consumption, standardization

\begin{abstract}
In developed countries, the mechanized agriculture is highly dependent on fuel. Unfortunately, the heterogeneity and complexity inherent to agricultural process do not help the actors (researchers, counselors, farmers) to improve fuel consumption efficiency in the farms. In order to measure precisely the use of the tractors this study proposes to rely on the embedded CAN bus technology and RTK positioning system implementing modern tractors to record fully characterized data of the engine load. This study demonstrates the feasibility of such proposition by testing specific dataloggers and software in-situ and by decoding signals to data and characterizing them.
\end{abstract}

\section{INTRODUCTION}

The increase of work intensity in the fields, the modernization of the techniques, the decrease of the qualified workforce, and the care for better working comfort lead the sector to rely increasingly on mechanized solutions. As a result, manufacturers of agricultural vehicles follow the demand and continually improve the power delivered, the steerability, the precision and automation of tasks. But the instability of the fuel markets and the announced declining oil reserves are persistent reminder that farmers should consider fuel consumption savings as an important lever to maintain farms income and competitiveness, or even sustainability. Unfortunately, the heterogeneity and complexity inherent to agricultural process complicate the production of advice by the actors (researchers, counselors, farmers) to improve fuel consumption efficiency in the farms, as experienced by Efficient20 project (2013).

The standardization of «CAN » (Controller Area Network) bus communication systems on agricultural tractors, from mid to high power range, open a wide range of opportunities for researchers in farm machinery and is considered by Grenier (2001) as a new field of data. Surprisingly, there are few examples of research valorizing these data, for example like Mattetti (2013) and Debroizze (2017). Furthermore, the manufacturers focus on the operational utility (monitoring of settings and mechanical failure, fleet management) through telematics (JDLink John Deere, PLM New Holland, etc.) without proposing analysis and Decision Support System (DSS).

Another step could be achieved if the CAN bus data were associated with the use of agricultural guidance systems by satellites. It could enhance the analysis to the agronomic level, giving context to CAN bus data (per field, per crops, pedologic and climatic conditions). Huyghebaert (2013) found that Guidance systems know an increasing demand from farmers because it largely facilitates control on field and improves comfort of the operator as well as the precision of work.

The main objective of the study was to determine the level of integration of CAN bus systems on modern agricultural tractors in Wallonia, their connectivity and their compliance to communication protocol standards. 


\section{MATERIAL AND METHOD}

Five tractors used in Wallonia were selected on the basis of the following criteria:

- Equipped with electronically controlled fuel injection (common rail)

- Representative of technical specificity of various groups of manufacturers (CNH, AGCO, SDF Group, John Deere)

- Covering a wide range of power and agricultural activities.

The average power of the tractor selected, presented in Table 1, is 178hp. All tractors are considered modern and non-obsolete, for an average year of construction 2010.

Table 1: Characteristics of selected tractors

\begin{tabular}{|l|c|c|c|c|c|}
\hline Brand & Case IH & John Deere & Deutz Fahr & $\begin{array}{c}\text { Massey } \\
\text { Ferguson }\end{array}$ & Fendt \\
\hline Model & Maxxum 115 & 6830 Premium & $\begin{array}{c}\text { Agrotron } \\
\text { M650 }\end{array}$ & 7619 & 826 \\
\hline $\begin{array}{l}\text { Year of } \\
\text { construction }\end{array}$ & 2007 & 2010 & 2007 & 2013 & 2013 \\
\hline $\begin{array}{l}\text { Nominal power } \\
{\left[\text { hp] }^{1}\right.}\end{array}$ & 117 & 145 & 185 & 185 & 260 \\
\hline $\begin{array}{l}\text { Transmission } \\
\text { Semi-Power } \\
\text { Shift }\end{array}$ & $\begin{array}{c}\text { Semi-Power } \\
\text { Shift }\end{array}$ & Power Shift & & Power Shift ${ }^{3}$ & $\begin{array}{c}\text { Continuous } \\
\text { variation }\end{array}$ \\
\hline Options & Front hitch & Front hitch & Front hitch & $\begin{array}{c}\text { Front hitch \& } \\
\text { PTO }\end{array}$ & $\begin{array}{c}\text { Front hitch \& } \\
\text { PTO }\end{array}$ \\
\hline
\end{tabular}

1 : brand official information

2 : synchronous ranges

3 : synchronous ranges and gears

Considering that the average nominal power of new tractor sold in Belgium in 2011 was 177hp (excluding tractor without CAN bus), the selection is considered as representative. The five brands concerned totalize together $57 \%$ of market share on a national scale (FEDAGRIM ASBL, 2014).

In order to record the CAN bus data, a datalogger Vector GL2000 was chosen for its ability to $\log$ simultaneously up to four CAN bus networks and to convert signals from electrical tension to bits. The datalogger has an integrated timer able to timestamp every data recorded with a 10-6 second resolution. The datalogger itself was configured to prevent any interaction with the networks, on a so called "no acknowledgement" mode (no ACK). Logging was activated on the four channels simultaneously on a standard baud rate for off-highway vehicles of 250Kbits/s (SAE, 2013). The internal timer was set to internet time and date before every recording. In an effort to record all the data at the time they are sent on the networks, the start and stop of the logging were set respectively on the "ON" and "OFF" position of the contact key.

Eventually, a multibrand diagnostic interface TEXA Navigator TXTs was used to determine the method to connect the datalogger to each tractor. Most CAN bus networks were not visible from the driver point of view in the cabs but the Navigator TXTs permitted to localize the access points to the networks and to identify the connector type installed and their active pins. These pins had to be tested to determine if there were connected either to CAN High wire of CAN Low wire. Thereafter, 
complete wired connections were developed to be able to connect the datalogger to each network.

The tractors were tested individually, always with the datalogger installed before electrical contact and ignition. To summarize, the datalogger was used as an embedded system, following each tractor during common use, from farm to fields. Duration of logging was not a controlled parameter, as all ECUs connected to the network must have communicated once before a limited time.

Post-treatment of the recordings was completed with CANalyzer software, primarily to compile the CAN bus bits structured in frames with three standard communication protocols for off-highway vehicles: SAE J1939 (SEA, 2013), ISO 11783 (ISO, 2017) and IEC 61162 (IEC, 2014). Consequently, standardized CAN frames, called "messages", are disaggregated in various CAN "signals", each one corresponding to a specific parameter (or data) communicated by the network. All the active CAN signals are sorted by their standard identifier and name, excluding the network diagnostic and management signals.

\section{RESULTS AND DISCUSSION}

Globally, the data retrieval had to deal with minor difficulties, except for the Deutz Fahr, in which the connections were still partially unidentified at the time this study was written. The CAN bus proved to be well integrated on the tested tractors and more importantly, predominantly in accordance with the current standards. The results are synthetized in Table 2.

Table 2: Characteristics of CAN bus communications

\begin{tabular}{|c|c|c|c|c|c|}
\hline Brand & Case IH & John Deere & Deutz Fahr & $\begin{array}{l}\text { Massey } \\
\text { Ferguson }\end{array}$ & Fendt \\
\hline CAN bus & 1 & 1 & 1 & 4 & 2 \\
\hline $\begin{array}{l}\text { Connector } \\
\text { number/type }\end{array}$ & $\begin{array}{c}\text { 1/Deutsch } \\
\text { HD10-9-1939 }\end{array}$ & $\begin{array}{c}\text { 1/Deutsch } \\
\text { HD10-9-1939 }\end{array}$ & $1 / ?$ & $\begin{array}{c}\text { 2/Deutsch } \\
\text { HD10-9-1939 }\end{array}$ & $\begin{array}{c}\text { 1/Deutsch } \\
\text { HD10-9-1939 }\end{array}$ \\
\hline $\begin{array}{l}\text { Total standard } \\
\text { frames }\end{array}$ & 24 & 44 & 31 & 54 & 54 \\
\hline $\begin{array}{l}\text { Non-standard } \\
\text { frames }\end{array}$ & 22 & 55 & 63 & 63 & 25 \\
\hline $\begin{array}{l}\text { Standardization } \\
\text { rate }[\%]^{1}\end{array}$ & 52 & 44 & 33 & 46 & 68 \\
\hline $\begin{array}{l}\text { SAE J1939 } \\
\text { signals }\end{array}$ & 97 & 103 & 109 & 194 & 207 \\
\hline $\begin{array}{l}\text { ISO } 11783 \\
\text { signals }\end{array}$ & $\begin{array}{c}\text { Not } \\
\text { implemented }\end{array}$ & 34 & $?$ & 54 & 92 \\
\hline $\begin{array}{l}\text { IEC } 61162 \\
\text { signals }\end{array}$ & 25 & $\begin{array}{c}\text { Not } \\
\text { implemented }\end{array}$ & $?$ & 25 & $\begin{array}{c}\text { Not } \\
\text { implemented }\end{array}$ \\
\hline Total signals & 122 & 137 & 109 & 273 & 299 \\
\hline
\end{tabular}

First of all, the majority of the CAN connectors, as provided by manufacturers, followed the J1939/13 standard specifications "Off-Board Diagnostic Connector" for trucks and tractors. The distribution of the nine pins is theoretically standardized as 
well, but minor adaptations were observed. The Deutz Fahr presented an unidentified connector.

The results obtained demonstrate a global trend of number of CAN, frames and signals related to the power and equipment level of the tractors.

Totals and subtotals of frames and signals number are listed in Table 2, without multiple counting. Two tractors (Case IH and Massey Ferguson) had integrated GPS devices communicating by IEC 61162 protocols. As the number of signals contained within the non-standard frames is not determined, Standardization rate of the CAN communication was calculated on basis of the frames number. It appeared clearly that an important part of the data was not usable as such, with a limited average standardization rate of $48.2 \%$ for the whole study. There are significant differences between the brands, even between Massey Ferguson and Fendt although they are both brands of AGCO Corporation. Nonstandard frames are considered as "proprietary", and designed by the brands themselves.

However, in terms of absolute value, the standardization permitted the retrieval of an unexpected number of signals, mainly under the J1939 protocol, confirming that CAN bus of tractors could represent an undervalued data field in agronomical research. The amount of readable signal as formal data varied from 109 (Deutz Fahr) to 299 (Massey Ferguson). Given the quantity and the wide variety of the signals recorded, it is difficult to present these results in a more detailed form in this study. In terms of homogeneity, the five tractors had 22 signals/7 frames) in common. This short list has still great potential for energy efficiency analysis, as shown in Table 3.

Table 3: Examples of signals involved in fuel consumption analysis and common to the five tractors

\begin{tabular}{|l|c|l|l|}
\hline Topic & Frame code & \multicolumn{1}{|c|}{ Signal name } & \multicolumn{1}{c|}{ Description } \\
\hline Motor configuration & EC1 & EngReferenceTorque $(\mathrm{Nm})$ & Theorical max. torque \\
\hline \multirow{4}{*}{ Motor management } & EEC1 & ActualEngPercentTorque $(\%)$ & Engine torque \\
\cline { 2 - 4 } & EEC1 & EngSpeed $(\mathrm{rpm})$ & Engine speed \\
\cline { 2 - 4 } & EEC1 & EngTorqueMode & Engine torque curve \\
\cline { 2 - 4 } & EEC2 & EngPercentLoadAtCurrentSpeed $(\%)$ & Instant. engine load \\
\hline \multirow{3}{*}{ Motor temperature } & ET1 & EngCoolantTemp $\left({ }^{\circ} \mathrm{C}\right)$ & Coolant liquid temp. \\
\cline { 2 - 4 } & ET1 & EngFuelTemp1 $\left({ }^{\circ} \mathrm{C}\right)$ & Fuel temp. \\
\hline Fuel management & LFE1 & EngFuelRate $(\mathrm{L} / \mathrm{h})$ & Instant. fuel consumpt. \\
\hline
\end{tabular}

All resolution and range of standards signals were in accordance with the three references.

Based on the time measurement of the datalogger, average frequencies were determined for all standard signals. The Figure 1 represents the distribution of the frequencies for signals standardized under J1939. 


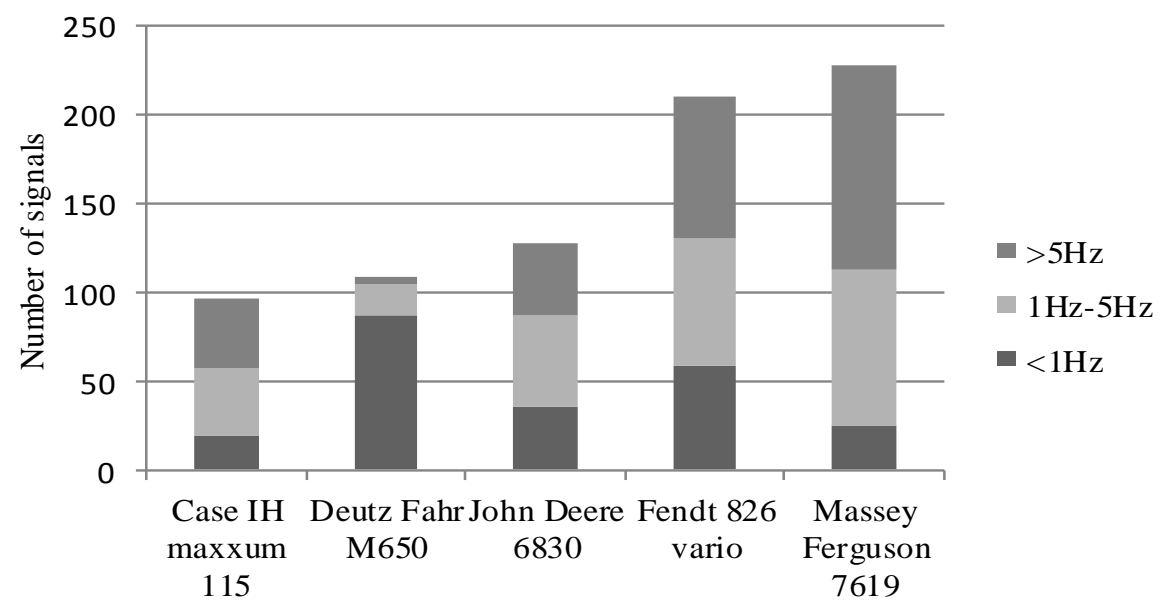

Figure 1. Distribution of the frequencies of J1939 signals by tractors

The Frequencies equal or above $1 \mathrm{~Hz}$ were the most represented. From the agronomical and operational points of view, in the conditions of use of a tractor, we assumed that a frequency above $1 \mathrm{~Hz}$ is adequate for most data analysis. For comparison, most guidance system used in agriculture work in the " $1 \mathrm{~Hz}-5 \mathrm{~Hz}$ " frequency class (RTK DGPS have a $5 \mathrm{~Hz}$ default set). The signals with low frequencies ( “ $<1 \mathrm{~Hz}$ " class) provide mostly "metadata" such as the configuration of the tractor (motor, ECUs, manufacturer ID, etc.), and they are subject to little or no variations.

Once again, the Deutz Fahr did not follow the trend of the other tractors and presented $80 \%$ of signals below $1 \mathrm{~Hz}$.

\section{CONCLUSIONS}

The main objective of the study was to determine the level of integration of CAN bus systems on five modern agricultural tractors in Wallonia, their connectivity and their compliance to communication protocol standards (SAE J1939, ISO 11783, EIC 61162), in order to allow more objective analysis of the fuel consumption in the farms.

First, the majority of the CAN connectors, as provided by manufacturers, followed the standard specifications for trucks and tractors. With a few adaptations, all the tractors were easily connected for recording. A large amount of data was then detected, but only half of it was standardized and readable, with significant differences between the brands. However, in terms of absolute value, the standardization permitted the retrieval of an unexpected number of signals, from 109 to 299 for the sampled tractors, mainly under the J1939 protocol. The five tractors shared 22 identical signals, comprising signals with direct interest for fuel consumption analysis. The results obtained demonstrate a global trend of number of CAN, frames and signals related to the power and equipment level of the tractors. A significant majority of signals are transmitted with frequencies equal or higher than $1 \mathrm{~Hz}$ which is considered adequate to analyze the activities of the tractors.

To conclude, results were globally considered as very encouraging. The good quality of the data acquired in terms of quantity, variety and frequency, and the highlight of standards data for fuel consumption analysis found on all studied tractors have proven the relevance of the approach, thanks to the well-integrated standardization. Finally the 
monitoring system developed during the study was selected for further research and implemented on tractors for long term recordings (1 year).

\section{ACKNOWLEDGEMENT}

This work is supported by the Walloon Region under the grant D31-1312 (Minesterial decree, 19th of December 2013) attributed to GéoCAN project. It also received the support of the Walloon Agricultural Research Centre.

\section{REFERENCES}

Debroize, D., \& Frédéric, G. (2017). Empirical fuel consumption model of tractor road travels. $1 s t$ AXEMA-EurAgEng Conference, Villepinte, France, 25 February 2017, 8 p.

Document IEC: 61162-3 Maritime navigation and radiocommunication equipment and systems - Digital interfaces - Part 3: Serial data instrument network (July 2014)

Document ISO: 11783-11 online data base (January 2017).

Document SAE: J1939-2 Agricultural an Forestry Off-Roade Machinery Control and Communication Network (March 2013).

Efficient20 project (2013). Results, lessons, impacts. Final publishable report. Efficient 20, VI EN. Intelligent Energy Europ, Project Database, 28p. European Commission.

FEDAGRIM ASBL. (2014). "D'avantage avec moins", analyse du secteur de l'équipement. Dossier Economique 2012-2013, FEDAGRIM, 88p.

Grenier, G. (2001). Bus CAN sur machines agricoles : les technologies de l'information au service de l'agriculture de précision et de la traçabilité. Ingénieries - EAT, 67-76.

Huyghebaert, B., Dubois, G., \& Defays, G. (2013). "Actual and global precision of the Guidance System AutoTrac from John Deere". EFITA-WCCA-CIGR Conference "Sustainable Agriculture through ICT Innovation”, Turin, Italy, 24-27 June 2013, 9p.

Mattetti, M., Molari, G., \& Sereni, E. (2013). "Method to measure the tractor operation parameters from CAN BUS". EFITA-WCCA-CIGR Conference "Sustainable Agriculture through ICT Innovation", Turin, Italy, 24-27 June 2013, 8p. 